\section{Estudo ecológico sobre os possíveis determinantes socioeconômicos, demográficos e fisiográficos do suicídio no Estado do Rio de Janeiro, Brasil, 1998-2002}

\author{
Socio-demographic determinants of suicide in the \\ State of Rio de Janeiro, Brazil, 1998-2002
}

\section{Abstract}

Epidemiology has identified violence as a major worldwide public health concern. Suicide is classified as violence. This study analyzes the association between suicide and socio-demographic factors. The methodological design was ecological, using correlation techniques and backward multiple linear regression. Normality of the residuals in the final model was analyzed. Proportional mortality in relation to total deaths was identified as the best outcome for modeling $\left(R^{2}=0.41\right)$. The resulting variables were: \% Pentecostal religion, \% single marital status in the population over 10 years of age, mean years of schooling, altitude of the municipality, \% homes without latrines, \% population over 10 years of age working in the educational sector, and \% population over 10 years with per capita earnings up to one minimum wage. All these variables were statistically significant at 5\%. The results support the idea of the influence of extrinsic causal factors in determination of suicide.

Suicide; Mortality; Risk Factors; Linear Models
José Gomes Bezerra Filho 1

Guilherme Loureiro Werneck 2,3

Rosa Lívia Freitas de Almeida 4

Maria Ivoneide Veríssimo de Oliveira 4

Francismeire Brasileiro Magalhães 5

\section{Introdução}

Nas últimas décadas tem havido um considerável aumento no nível de violência, principalmente nos grandes centros urbanos onde adquiriu caráter epidêmico. A epidemiologia tem focalizado esse problema como um dos principais no campo da Saúde Pública em todo o mundo.

Dentre as diversas categorias da violência, encontra-se o suicídio definido como a ação de tirar a própria vida de forma intencional e voluntária realizada por uma pessoa com pleno conhecimento do resultado fatal 1 . Corroborando com essa afirmação, o Relatório Mundial sobre Violência e Saúde elaborado pela Organização Mundial da Saúde (OMS) classifica a violência autoinfligida em comportamento suicida e agressão autoinfligida. O primeiro, inclui pensamentos suicidas, tentativas de suicídio e o suicídio propriamente, também denominado tecnicamente de comportamento suicida fatal 2 .

Em termos globais, a mortalidade por suicídio aumentou $60 \%$ nos últimos 45 anos. Na maioria dos países, o suicídio situa-se entre as 10 causas mais frequentes de morte e entre as duas ou três mais comuns em adolescentes e adultos jovens 3 .

A taxa de suicídio por 100 mil habitantes na maior parte dos países da América do Sul é inferior a 6,5. Estados Unidos, Canadá, Portugal, Espanha, Alemanha, Índia e Austrália apresentam 
taxas de 6,5 a 13. Na França, Suécia, Rússia, China e Japão as taxas ficam acima de 13. Os países bálticos possuem taxas entre 32 e 42, a exemplo da Lituânia $(41,9)$, Estônia $(40,1)$, Rússia $(37,6)$, Letônia $(33,9)$ e Hungria $(32,9)$ e são os recordistas em média de suicídio por 100 mil habitantes. Já a Guatemala, Filipinas e Albânia estão no lado oposto, com as menores taxas, variando entre 0,5 e 24 .

Reportando-se ao Brasil, ocorreram no ano de 2007, 131.032 óbitos por causas externas (acidentes e violências). Desse total, o suicídio respondeu por 8.868 óbitos, $6,8 \%$ de mortes por causas externas, com taxa de mortalidade específica de 4,68 óbitos por 100 mil habitantes (Departamento de Informática do SUS. http://tabnet.datasus. gov.br/cgi/tabcgi.exe?sim/cnv/ext10uf.def, acessado em 08/Dez/2009). O comportamento suicida exerce considerável impacto nos serviços de saúde, e calcula-se que $1,4 \%$ da carga global ocasionada por doenças no ano 2002 ocorreu devido às tentativas de suicídio. Essa cifra deverá chegar aos $2,4 \%$ em 20203.

A taxa de suicídio no Brasil, embora ainda apontada como baixa numa escala global, cresceu $21 \%$ no período $1980-2000$ seguindo tendência mundial. Os homens cometeram suicídio de 2 a 4 vezes mais que as mulheres dependendo da região. Em alguns grupos populacionais nas grandes cidades como o de idosos acima de 65 anos (com as maiores taxas) e dentre jovens com idades entre 15 e 24 anos (com o maior incremento na taxa), ou de indígenas no Centro-oeste e no Norte bem como entre lavradores do interior do Rio Grande do Sul, as cifras se aproximam ou superam as de países do leste europeu e da Escandinávia 3,5 .

No período de 1998 a 2006, as taxas de suicídio nas capitais do Brasil variaram desde um máximo de 9,5 por 100 mil habitantes em Boa Vista a um mínimo de 1,3 por 100 mil em Salvador. As cinco primeiras capitais com as maiores taxas médias de suicídios por 100 mil habitantes no mesmo período foram: Boa Vista $(9,5)$, Macapá $(8,3)$, Porto Alegre $(8,2)$, Florianópolis $(7,4)$ e Rio Branco $(7,0)$, sendo todas elas maiores entre os homens, inclusive em todas as capitais do Brasil 6 .

Analisando a série de 1996 a 2005, as maiores taxas do Estado do Rio de Janeiro para homens e mulheres, respectivamente, foram 4,77 em 2001 e 1,83 em 2002. No ano de 2005, o Rio de Janeiro apresentou taxa de mortalidade por suicídio de 2,56 óbitos por 100 mil habitantes. Essa taxa situou o estado em 21o lugar no ranking nacional.

Essas diferenças entre nações e inter-regionais têm instigado pesquisadores de vários campos que apontaram a etnia, a cultura, as crises sociais e inclusive aspectos climáticos como possíveis fatores ligados ao problema do suicídio 7 , no entanto, existem poucos trabalhos regionalizados que consideram as características demográficas, sociais, econômicas, culturais e de miscigenação racial da população brasileira ${ }^{8}$.

O suicídio é um fenômeno estudado em diversas áreas do conhecimento, tanto nas artes como nas ciências. Na perspectiva individual tornou-se objeto de estudo da psiquiatria, psicologia, psicanálise e filosofia; no coletivo, torna-se objeto da antropologia, demografia, epidemiologia, entre outras. Durkheim 9 fez uma relação direta entre as formas de suicídio e a divisão do trabalho. Ele acreditava que se pudesse demonstrar o quanto um ato individual poderia ser resultante do meio social. Nesse plano teórico, Durkheim ${ }^{9}$, baseado no grau de desequilíbrio de duas forças: integração social e regulação moral, propôs a categorização de quatro tipos de suicídio: do egoísta motivado pelo isolamento do indivíduo em relação à sociedade, ao altruísta em que o indivíduo encontra-se demasiadamente ligado à sociedade, do anômico caracterizado pela insatisfação com as condições de vida, ao fatalista que se entrega aos acontecimentos que classifica como destino 9,10 . Os principais fatores de risco apontados por organismos internacionais como a Organização Pan-Americana da Saúde (OPAS) e a OMS para o suicídio podem ser de ordem sociodemográfica, psiquiátrica, psicológica e das condições clínicas incapacitantes 11,12.

Durkheim 13, em um estudo sociológico do suicídio no século XIX, utilizando as estatísticas de mortalidade, analisou esse fenômeno como um evento coletivo e valorizou as suas causas sociais. Destaca haver maior prevalência do suicídio nas regiões protestantes, nas áreas urbanas e entre as pessoas de maior escolaridade 9 .

Diante do exposto, pode-se inferir que suicídio possui duas vertentes de análise constituídas por fatores relacionados aos contextos social e interpessoal aos quais o indivíduo está inserido, ou seja, determinantes de ordem intrínseca e os determinantes de ordem extrínseca, sendo estes o foco principal deste trabalho. Muito embora tal divisão seja meramente facilitadora da compreensão desses fatores, ressalta-se que sua atuação ocorra de forma conjunta e articulada. Pode-se afirmar, portanto, que o suicídio demanda ações intersetoriais de enfrentamento para a redução dos casos, porquanto seu estudo assume caráter multidisciplinar e transdisciplinar.

O presente estudo pretende investigar as associações entre o suicídio e os aspectos socioeconômicos, demográficos e fisiográficos no Estado do Rio de Janeiro, no período de 1998 a 2002, identificando aspectos extrínsecos, ou seja, considerando os fatores ambientais, sociais e 
de saúde, somente possível de captá-los no nível agregado.

\section{Metodologia}

A abordagem metodológica utilizada foi do tipo ecológico transversal, usando-se técnica de análise espacial, realizada no período de 1998 a 2002, tomando-se como unidades de análise os 91 municípios do Estado do Rio de Janeiro. O estudo ecológico do suicídio permite examinar como a composição, características e recursos de uma área modelam as interações sociais e os desfechos em saúde 14. Utilizamos o referencial teórico de inspiração durkheimiana no qual as correlações funcionais entre as diversas variáveis só admitem observar, comparar e explicar um fato social por um outro fato social. Aqui reside a fundamentação teórica do confronto entre indicadores epidemiológicos e indicadores socioeconômicos, demográficos e fisiográfcos no processo de modelagem.

\section{Variáveis de estudo}

As variáveis foram coletadas, via Internet, das páginas do Sistema IBGE de Recuperação Automática (SIDRA-IBGE), Sistema de Informações sobre Mortalidade (SIM-DATASUS) e Instituto de Pesquisa Econômica Aplicada (IPEA). O conjunto das variáveis investigadas justifica-se por tratarse, inicialmente, de um estudo exploratório, sendo que para a escolha destas variáveis prevaleceu além daquelas apontadas na literatura, as que de forma inovadora poderiam relacionar-se com o desfecho em questão.

A epidemiologia apresenta um conjunto diversificado de indicadores cada um com suas peculiaridades. Neste trabalho foram investigados como desfecho o suicídio (X-60 a X-84), pela 10a revisão da Classificação Internacional de Doenças (CID-10), por intermédio dos seguintes indicadores: taxa de suicídio (número de óbitos por suicídio pela população sob risco por 100 mil habitantes), mortalidade proporcional por suicídio em relação ao total de óbitos e em relação ao total de óbitos por causas externas, taxa dos anos potenciais de vida perdidos (TAPVP) conforme técnica desenvolvida por Romeder \& McWhinnie 15 e razão de mortalidade padronizada pelo método indireto (RMP) 16 no período 1998-2002.

Com relação às variáveis preditoras foram selecionadas de acordo com os grupos: demografia (população: proporção da população residente na área urbana; raça/cor: proporção da população parda; estado civil: pessoas com 10 anos ou mais de idade por estado civil solteiro; religião: proporção da população residente com religião de origem pentecostal), educação (analfabetos de 15 anos ou mais de idade, média de anos de estudos), ocupação (proporção de pessoas desocupadas, pessoas com 10 anos ou mais de idade ocupadas em atividade de trabalho principal no setor de educação, pessoas com 10 anos ou mais de idade ocupadas em atividade de trabalho principal no setor de agricultura, pecuária, silvicultura e exploração florestal), renda (proporção de moradias inadequadas, proporção de pessoas com 10 anos ou mais de idade com classe de rendimento nominal de até um salário mínimo, razão entre a renda dos $10 \%$ mais ricos e $40 \%$ mais pobres e proporção de residências com ar condicionado), fisiografia (estimativas das médias trimestrais de temperatura: outono (março/maio $-{ }^{\circ} \mathrm{C}$, estimativas das médias trimestrais de precipitação pluviométrica: inverno (junho/ agosto - mm/mês) e saneamento (proporção de moradores em domicílios permanentes com coleta de lixo).

\section{Análise dos dados}

Foi utilizada análise de correlação de Pearson para selecionar dentre os diversos desfechos (taxa, mortalidade proporcional, TAPVP e RMP) aquele que melhor se associava aos indicadores socioeconômicos, demográficos e fisiográficos. Feito isso, foram eleitos para o modelo inicial aqueles fatores cuja correlação linear com o desfecho eleito fosse estatisticamente significante no nível de $20 \%$ e, simultaneamente, não apresentassem correlação importante $(|r|>0,5)$ entre os fatores 17. Posteriormente, foi empreendida a regressão linear múltipla com a seleção de variáveis do tipo backward para identificar quais indicadores melhor, segundo critérios de análise residual e coeficiente de determinação, explicava o desfecho selecionado. Após a obtenção desse modelo, foi novamente avaliada a colinearidade entre as variáveis preditoras, adotando como critério o fator de inflação de variação (VIF) inferior a 4. Essa etapa foi realizada utilizando-se o Stata 10 (Stata Corp., College Station, Estados Unidos).

A análise exploratória da distribuição espacial dos indicadores epidemiológicos (taxa e proporção) teve como finalidade identificar o padrão espacial por meio de mapas temáticos relativos às unidades territoriais de análise (municípios), para tanto foi utilizado o mapa digital do Estado do Rio de Janeiro, mostrando as áreas de maior gravidade do problema. 


\section{Resultados}

No período de 1998 a 2002, a taxa de suicídio no Estado do Rio de Janeiro no sexo masculino foi de 4,41 com variação entre os seus municípios de 0,00 a 28,07 por 100 mil homens e, para o sexo feminino, de 1,34 com variação intermunicipal de 0,00 a 10,25 por 100 mil mulheres, resultado da efetivação de 1.508 óbitos no sexo masculino e 497 no feminino, o que fez o Rio de Janeiro contribuir no período em questão com 5,6\% dos suicídios do Brasil. Com relação à mortalidade proporcional às mortes autoprovocadas representaram $0,46 \%$ e $0,20 \%$ de todos os óbitos masculinos e femininos, respectivamente, e $2,32 \%$ e $4,21 \%$ do total de óbitos por causas externas, no período de 1998 a 2002, no Estado do Rio de Janeiro.

Os municípios de Aperibé, Arraial do Cabo, Comendador Levy Gasparian, Macuco, Silva Jardim e Varre-Sai apresentaram frequências nulas no quinquênio estudado e, portanto, todos os indicadores epidemiológicos também foram nulos. No entanto, a Tabela 1 apresenta o ranking dos dez municípios com menores e maiores valores correspondentes aos indicadores epidemiológicos trabalhados. As Figuras 1 e 2 mostram as distribuições espaciais da taxa de mortalidade e da mortalidade proporcional por suicídio no Estado do Rio de Janeiro.

A mortalidade proporcional em relação ao total de óbitos foi eleita como o melhor desfecho para modelagem $\left(\mathrm{R}^{2}=0,41\right)$ dentre aqueles cogitados na metodologia, conforme modelo apresentado na Tabela 2 . As variáveis resultantes associadas foram: percentual da população residente com religião de origem pentecostal ( $\left.\beta^{\prime}=-0,239\right)$ como covariável principal ajustada pelas seguintes covariáveis secundárias: porcentual de pessoas com 10 anos ou mais de idade por estado civil solteiro $\left(\Omega^{\prime}=-0,221\right)$, média de anos de estudos $\left(\Omega^{\prime}=0,394\right)$, altitude em metros para os municípios da divisão político-administrativa vigente em $2000\left(\Omega^{\prime}=0,188\right)$, porcentual de moradores em domicílios particulares permanentes com ausência de banheiro $\left(\Omega^{\prime}=0,308\right)$, porcentual de pessoas com 10 anos ou mais de idade ocupadas no setor "educação" $\left(\beta^{\prime}=0,211\right)$ e porcentual de pessoas com 10 anos ou mais de idade com rendimento nominal de até um salário mínimo $\left(\Omega^{\prime}=-0,349\right)$, todas estatisticamente significantes no nível de $5 \%$ pelo teste de Wald e dentro de padrões aceitáveis com relação à colinearidade.

Um aspecto importante desse resultado é ter clareza de que suas variáveis preditoras não podem ser interpretadas de forma individualizada, mas na forma ajustada pelas demais variáveis constantes do modelo, e que a utilização dos coe- ficientes de regressão padronizados clarifica e ordena a magnitude da relação com o desfecho no modelo considerado; portanto, o valor nulo do coeficiente da regressão, com aproximação para três casas decimais, para a variável "Altitude" de fato é melhor evidenciado na forma padronizada. Nesse modelo o VIF não excluiu nenhum dos fatores.

\section{Discussão}

Os estudos ecológicos podem, particularmente, avaliar como os contextos social e ambiental podem afetar a saúde de grupos populacionais. Nesse caso, as medidas coletadas no nível individual são incapazes de refletir adequadamente os processos que ocorrem no nível coletivo.

O principal risco da análise ecológica na produção da inferência causal é o de transgressão dos níveis de análise, ou seja, esperar que estimativas do efeito ecológico reflitam o efeito no nível individual. No entanto, também estão presentes outras dificuldades, tais como o confundimento, a interação, a colinearidade comum entre variáveis socioeconômicas, a superdispersão relativa a regiões com pequenos contingentes populacionais expostos e a autocorrelação espacial, regiões vizinhas tendendo a apresentar taxas mais similares que regiões distantes 18,19,20.

Como esses estudos têm como base as médias de populações, o nível de associação entre a exposição e o desfecho geralmente é mais tênue e pode, em alguns casos, ser oposta à do nível individual. Apesar de indicar os fatores associados, frente à multiplicidade de resultados possíveis, a importância de cada um deles varia de acordo com o modelo apresentado, o que restringe sua aplicabilidade na orientação da prevenção 20,21.

Apesar dessas limitações, existem muitas razões para o uso dos estudos ecológicos em epidemiologia, dentre as quais destacam-se: o baixo custo por trabalhar, geralmente, com dados secundários; maior facilidade no trato de variáveis, quando existe limitação quanto à mensuração pela sua natureza ou por dificuldades de aferição, o que as torna de difícil obtenção no nível individual; interesse em efeitos ecológicos; e por último o senso de oportunidade, levando em consideração o nível de desenvolvimento das técnicas de análise, orientadas ao manejo das dificuldades pertinentes ao modelo de estudo em questão.

A informação potencialmente mais importante reproduzida por este estudo diz respeito à nova visão da morbimortalidade por suicídio, que embora reconhecido pela OMS 12 como um transtorno multidimensional resultante de inte- 
Ranking municipal das dez mais baixas e dez mais altas mortalidades por suicídio no Estado do Rio de Janeiro, Brasil, segundo principais indicadores epidemiológicos, no período de 1998-2002.

\begin{tabular}{|c|c|c|c|c|c|c|c|c|c|c|}
\hline \multirow{2}{*}{$\begin{array}{l}\text { Ordem } \\
\text { 1으 }\end{array}$} & \multicolumn{2}{|c|}{$\begin{array}{c}\text { Taxa de } \\
\text { mortalidade }\end{array}$} & \multicolumn{2}{|c|}{$\begin{array}{c}\text { Proporção em relação } \\
\text { ao total de óbitos }\end{array}$} & \multicolumn{2}{|c|}{$\begin{array}{c}\text { Proporção em relação } \\
\text { a causas externas }\end{array}$} & \multicolumn{2}{|l|}{ TAPVP } & \multicolumn{2}{|l|}{ RMP } \\
\hline & Japeri & 0,48 & Japeri & 0,07 & Japeri & 0,46 & Japeri & 0,11 & Japeri & 0,20 \\
\hline 2으 & Natividade & 1,31 & Natividade & 0,18 & Belford Roxo & 1,27 & Iguaba Grande & 0,21 & Natividade & 0,47 \\
\hline 3으 & São Gonçalo & 1,33 & São Gonçalo & 0,19 & São Gonçalo & 1,30 & Natividade & 0,34 & São Gonçalo & 0,48 \\
\hline 4으 & Belford Roxo & 1,43 & Nova Iguaçu & 0,20 & Nova Iguaçu & 1,35 & São Gonçalo & 0,36 & Nova Iguaçu & 0,53 \\
\hline 5으 & Nova Iguaçu & 1,56 & Belford Roxo & 0,21 & Itaguaí & 1,43 & $\begin{array}{l}\text { São João de } \\
\text { Meriti }\end{array}$ & 0,36 & Belford Roxo & 0,56 \\
\hline 6o & Guapimirim & 1,58 & São João de Meriti & 0,22 & Duque de Caxias & 1,45 & Nova Iguaçu & 0,37 & Guapimirim & 0,60 \\
\hline 7으 & $\begin{array}{l}\text { Duque de } \\
\text { Caxias }\end{array}$ & 1,59 & Duque de Caxias & 0,23 & Guapimirim & 1,61 & Belford Roxo & 0,39 & $\begin{array}{l}\text { Duque de } \\
\text { Caxias }\end{array}$ & 0,61 \\
\hline 8으 & $\begin{array}{l}\text { São João de } \\
\text { Meriti }\end{array}$ & 1,66 & Guapimirim & 0,24 & São João de Meriti & 1,62 & Duas Barras & 0,40 & $\begin{array}{l}\text { São João de } \\
\text { Meriti }\end{array}$ & 0,63 \\
\hline 9으 & Porto Real & 1,78 & Itaguaí & 0,25 & Macaé & 1,89 & $\begin{array}{c}\text { Casimiro de } \\
\text { Abreu }\end{array}$ & 0,41 & Porto Real & 0,68 \\
\hline $\begin{array}{l}10 \text { 으 } \\
\ldots\end{array}$ & Volta Redonda & 1,90 & Rio Bonito & 0,26 & Rio Bonito & 1,96 & Rio Bonito & 0,42 & Volta Redonda & 0,69 \\
\hline 82 으 & Miguel Pereira & 7,01 & Cardoso Moreira & 1,02 & Miguel Pereira & 10,96 & Quissamã & 2,01 & Teresópolis & 2,51 \\
\hline 83으 & $\begin{array}{l}\text { Santa Maria } \\
\text { Madalena }\end{array}$ & 7,62 & $\begin{array}{l}\text { Santa Maria } \\
\text { Madalena }\end{array}$ & 1,06 & Quatis & 11,11 & Nova Friburgo & 2,01 & $\begin{array}{l}\text { Santa Maria } \\
\text { Madalena }\end{array}$ & 2,66 \\
\hline 84으 & Bom Jardim & 7,90 & São José de Ubá & 1,08 & Laje do Muriaé & 11,76 & São Fidélis & 2,02 & Bom Jardim & 2,81 \\
\hline 85 으 & Cardoso Moreira & 8,17 & Bom Jardim & 1,10 & $\begin{array}{c}\text { Santa Maria } \\
\text { Madalena }\end{array}$ & 13,79 & Cardoso Moreira & 2,31 & Cardoso Moreira & 2,83 \\
\hline 860 & Sumidouro & 8,54 & $\begin{array}{l}\text { Bom Jesus do } \\
\text { Itabapoana }\end{array}$ & 1,19 & Cantagalo & 14,29 & Miguel Pereira & 2,52 & Sumidouro & 3,15 \\
\hline 87으 & $\begin{array}{l}\text { Bom Jesus do } \\
\text { Itabapoana }\end{array}$ & 9,46 & Porciúncula & 1,27 & Italva & 14,29 & $\begin{array}{l}\text { Bom Jesus do } \\
\text { Itabapoana }\end{array}$ & 2,74 & $\begin{array}{l}\text { Bom Jesus do } \\
\text { Itabapoana }\end{array}$ & 3,38 \\
\hline 88으 & Porciúncula & 9,96 & Italva & 1,34 & Sumidouro & 14,29 & Porciúncula & 2,91 & Italva & 3,61 \\
\hline 89 으 & Piraí & 10,27 & Piraí & 1,38 & $\begin{array}{l}\text { São Sebastião do } \\
\text { Alto }\end{array}$ & 16,67 & Italva & 3,01 & Porciúncula & 3,65 \\
\hline 90으 & Italva & 10,81 & Sumidouro & 1,48 & $\begin{array}{l}\text { Bom Jesus do } \\
\text { Itabapoana }\end{array}$ & 17,78 & Piraí & 3,07 & Piraí & 3,72 \\
\hline 91으 & $\begin{array}{c}\text { São Sebastião } \\
\text { do Alto }\end{array}$ & 16,69 & $\begin{array}{l}\text { São Sebastião do } \\
\text { Alto }\end{array}$ & 2,30 & Porciúncula & 17,78 & $\begin{array}{l}\text { São Sebastião } \\
\text { do Alto }\end{array}$ & 3,59 & $\begin{array}{l}\text { São Sebastião } \\
\text { do Alto }\end{array}$ & 5,83 \\
\hline
\end{tabular}

RMP: razão de mortalidade padronizada pelo método indireto; TAPVP: taxa dos anos potenciais de vida perdidos.

Nota: excluem-se os municípios com frequência nula no período 1998-2002.

rações entre fatores ambientais, sociais, psicológicos e biológicos ainda é pouco valorizada a determinação de seus aspectos extrínsecos.

De acordo com Durkheim 13, os seres humanos têm um certo nível de integração com os seus grupos, que ele chama de vínculo social, e é composto por dois fatores: integração social (ligação a outros indivíduos dentro da sociedade) e regulação moral (ligação com as normas da sociedade). Níveis anormalmente baixos de integração social podem resultar num aumento do suicídio: “o suicídio varia na razão inversa do grau de integração dos grupos sociais de que o indivíduo faz parte" 13 (p. 204). O trabalho de Durkheim influenciou os proponentes da Teoria do Controle, e é frequentemente mencionado como um estudo sociológico clássico 7,9.

A OMS 2 em seu Relatório Mundial sobre Violência e Saúde propõe um modelo de estudo ecológico baseado em quatro níveis. O primeiro nível do modelo procura identificar tanto os fatores biológicos como os da história pessoal que um indivíduo traz para o seu comportamento. O segundo explora como as relações sociais próximas 

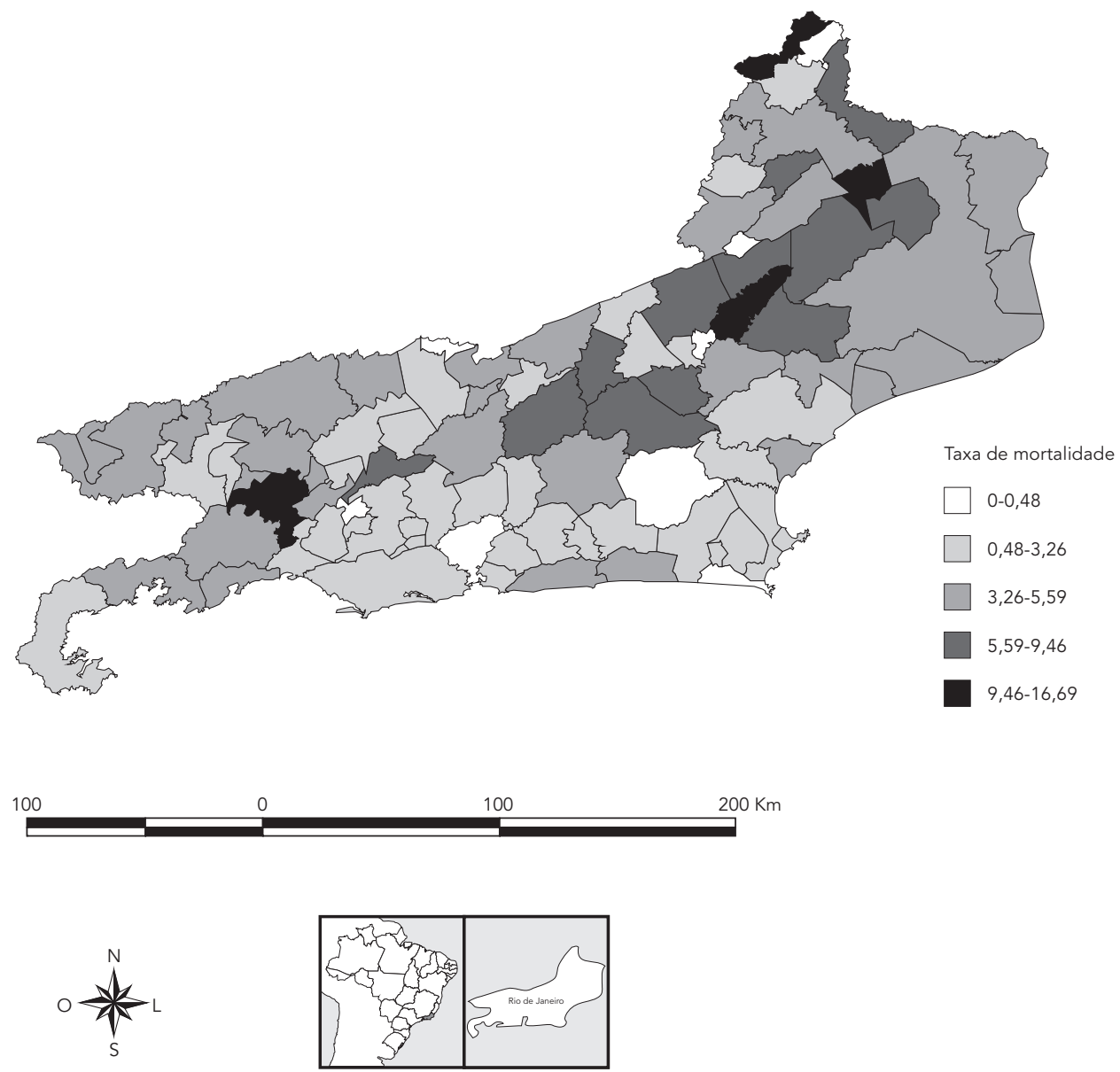

aumentam o risco de vitimização ou agressão violenta. O terceiro nível examina os contextos comunitários nos quais estão inseridas as relações sociais, tais como escolas, locais de trabalho etc. O quarto e último examina os fatores mais significativos da sociedade que influenciam as taxas de violência. Aqui, estão aqueles fatores que criam um clima aceitável para a violência, aqueles que diminuem as inibições contra ela e aqueles que criam e sustentam divisões entre diferentes segmentos da sociedade ou tensões entre grupos ou países diferentes. Estão entre os fatores significativos da sociedade: (1) normas culturais que sustentam a violência como forma aceitável para resolver conflitos; (2) atitudes que consideram o suicídio como uma questão de escolha individual em vez de um ato de violência evitável; (3) normas que dão prioridade aos direitos dos pais sobre o bem-estar da criança; (4) normas que fixam o domínio masculino sobre as mulheres e crianças; (5) normas que apoiam o uso excessivo da força pela polícia contra os cidadãos; (6) normas que apoiam o conflito político. Estão também incluídos entre os fatores relevantes da sociedade as políticas de saúde, educacionais, econômicas e sociais que mantêm altos níveis de desigualdade econômica ou social entre grupos 2 .

A proposta ecológica enfatiza as múltiplas causas da violência e a interação dos fatores de risco que operam no interior da família e dos contextos mais amplos da comunidade, como os contextos social, cultural e econômico. Colocado em um contexto de desenvolvimento, o modelo 

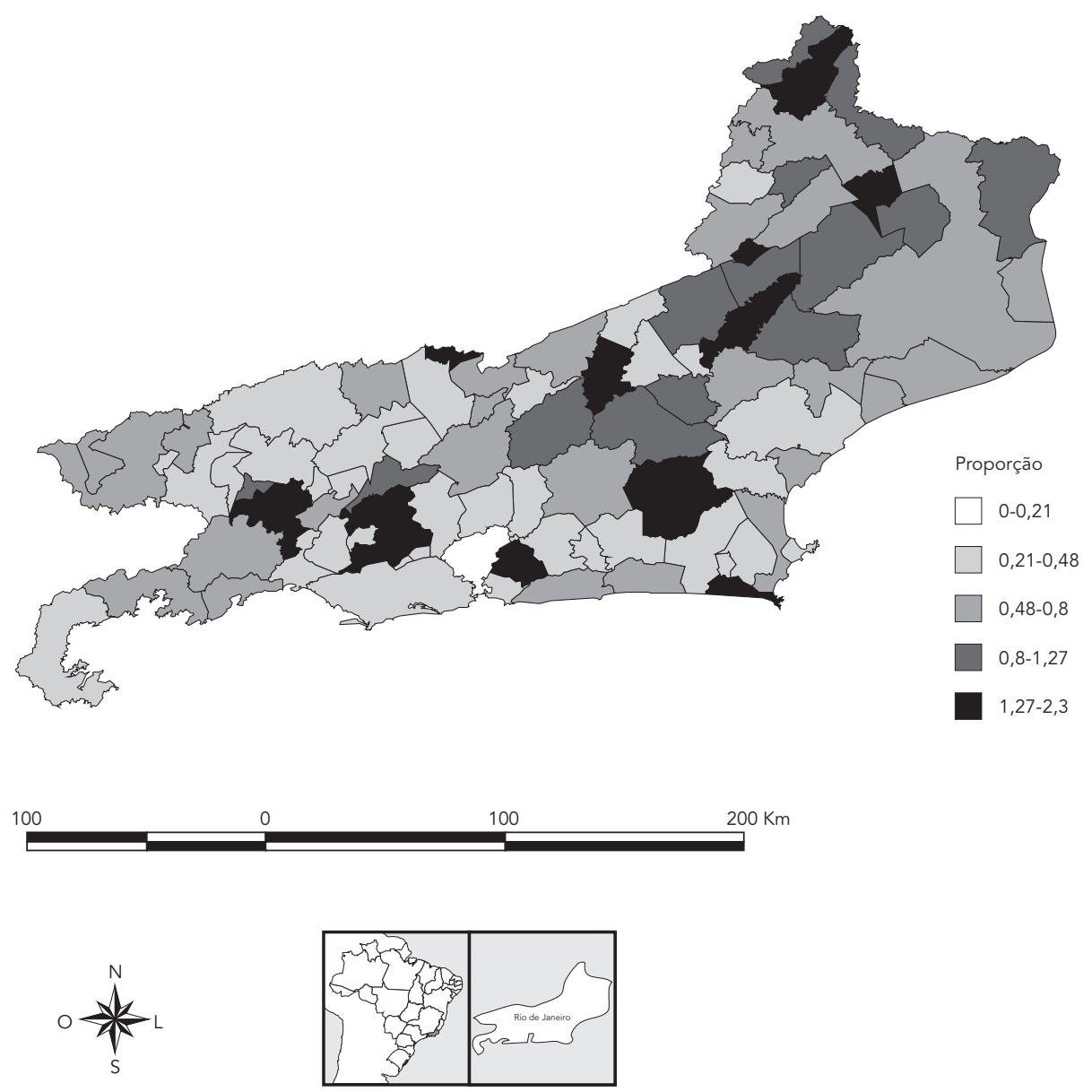

ecológico mostra como a violência pode ser causada por diferentes fatores em etapas diversas da vida 2 .

\section{Modelo}

Adeptos ou não da ideia de relação entre religião e suicídio, mais uma vez constata-se esta associação. Tal resultado vem corroborar com a literatura mais atualizada que discute o assunto. Nesse sentido, Almeida \& Lotufo Neto 22 realizaram uma vasta revisão e concluíram que o mais importante não é a denominação religiosa na qual o indivíduo professa, e sim a sua prática religiosa que funciona como fator de proteção contra ideação, tentativa e atos autodestrutivos, assim como atitude mais tolerante ao suicídio, daí a constatação de quanto maior a proporção de pentecostais na população menor a taxa de suicídio no modelo considerado, levando-se em conta que os protestantes são praticantes 22.

Em Atenas, Grécia, no século IV, cortava-se a mão direita daquele que cometera o suicídio. Essa era enterrada distante do resto do corpo do individuo de forma a evitar uma posterior vingança do morto. O objetivo era desfazer seu estratagema, destituí-lo de poder, da capacidade de assassinar os vivos. Ainda no século IV, Santo Agostinho assinala que o suicídio era uma "perversão detestável” e “demoníaca”, e que o "não matarás”, um dos mandamentos do cristianismo, estendia-se também a "não matarás a si próprio". Para os cristãos o suicídio era entendido como desesperança, portanto considerado pecado 
Tabela 2

Modelo de regressão linear múltipla com base nos possíveis determinantes socioeconômicos e demográficos da mortalidade proporcional por suicídio para os municípios do Estado do Rio de Janeiro, Brasil, no período de 1998-2002.

\begin{tabular}{|c|c|c|c|c|c|c|c|c|}
\hline \multirow{2}{*}{$\begin{array}{l}\text { Desfecho: mortalidade } \\
\text { proporcional por suicídio em } \\
\text { relação ao total de óbitos } \\
\text { em ambos os sexos }\end{array}$} & \multicolumn{2}{|c|}{$\begin{array}{c}\text { Coeficiente não } \\
\text { padronizado }\end{array}$} & \multirow{2}{*}{$\begin{array}{c}\text { Coeficiente } \\
\text { padronizado } \\
\beta\end{array}$} & \multirow[t]{2}{*}{$\begin{array}{c}\text { t de } \\
\text { Student }\end{array}$} & \multirow[t]{2}{*}{$\begin{array}{l}\text { Valor } \\
\text { de } p\end{array}$} & \multirow[t]{2}{*}{ IC95\% } & \multicolumn{2}{|c|}{$\begin{array}{l}\text { Estatística de } \\
\text { colinearidade }\end{array}$} \\
\hline & $\beta$ & EP & & & & & Tolerância & VIF \\
\hline Constante & 1,120 & 0,540 & & 2,076 & 0,041 & $\begin{array}{l}0,047 \\
2,194\end{array}$ & & \\
\hline \% de religião pentecostal & $-0,017$ & 0,008 & $-0,239$ & $-2,230$ & 0,028 & $\begin{array}{l}-0,033 \\
-0,002\end{array}$ & 0,612 & 1,633 \\
\hline$\%$ de estado civil solteiro & $-0,019$ & 0,010 & $-0,221$ & $-1,952$ & 0,054 & $\begin{array}{l}-0,039 \\
0,000\end{array}$ & 0,551 & 1,814 \\
\hline Média de anos estudos & 0,020 & 0,008 & 0,394 & 2,550 & 0,013 & $\begin{array}{l}0,004 \\
0,036\end{array}$ & 0,296 & 3,382 \\
\hline Altitude em metros & 0,000 & 0,000 & 0,188 & 1,978 & 0,051 & $\begin{array}{l}0,000 \\
0,001\end{array}$ & 0,782 & 1,279 \\
\hline $\begin{array}{l}\% \text { de moradores em domicílios sem } \\
\text { banheiro }\end{array}$ & 0,071 & 0,026 & 0,308 & 2,683 & 0,009 & $\begin{array}{l}0,018 \\
0,123\end{array}$ & 0,536 & 1,864 \\
\hline $\begin{array}{l}\text { \% de pessoas ocupadas atividades } \\
\text { principal educação }\end{array}$ & 0,040 & 0,020 & 0,211 & 2,008 & 0,048 & $\begin{array}{l}0,000 \\
0,079\end{array}$ & 0,640 & 1,562 \\
\hline $\begin{array}{l}\text { \% de pessoas renda até } 1 \text { salário } \\
\text { mínimo }\end{array}$ & $-0,021$ & 0,010 & $-0,349$ & $-2,135$ & 0,036 & $\begin{array}{l}-0,040 \\
-0,001\end{array}$ & 0,265 & 3,777 \\
\hline
\end{tabular}

$\mathrm{N}=91 ; \mathrm{R}^{2}=0,41$.

EP: erro padrão; IC95\%: intervalo de 95\% de confiança; VIF: fator de inflação de variação.

grave 23. Na Idade Média, período caracterizado por uma maciça dominação religiosa, o suicídio diminuiu, pois quem o cometesse não recebia as bênçãos da Igreja. Na Renascença, período de maior liberdade religiosa, o suicídio recrudesceu e continua até nos dias atuais, principalmente explicados pelos problemas causados pela revolução industrial e pelo capitalismo nascente, os quais diminuíram os apelos à religião 4 .

Outras religiões também condenavam o suicídio. No judaísmo, o suicida não é sepultado de acordo com o ritual utilizado normalmente, Kaddish, é enterrado longe dos demais. A religião judaica entende o suicídio como um crime dirigido a Deus. O suicídio é condenado no Deuteronômio, quinto livro do Pentateuco (conjunto dos cinco primeiros livros da Bíblia) 23. Os espíritas discutem a questão do suicídio inconsciente, ou seja, o ato praticado de forma involuntária associado ao vício ou a transtorno de ordem psíquica, em que o indivíduo perderia, mesmo que temporariamente, a consciência da gravidade do ato empreendido a ponto de ter sua capacidade de racionalidade destituída 4 .

Os aspectos culturais possuem uma grande influência nos casos de suicídio e variam de acor- do com cada sociedade. O Japão, por exemplo, um país de primeiro mundo, também é conhecido pelas altas taxas de suicídio. A história do suicídio no Japão remonta a períodos antigos. Os samurais que faziam parte de uma elevada classe social, não existem há mais de um século, porém alguns resquícios sobrevivem ao tempo. A morte era um dever, o suicídio altruísta nos termos de Durkheim. O gesto de se matar tornou-se mais e mais solene, preciso e ritual. Foi o procedimento que se impôs sob o nome de seppuku, forma polida que designa "ventre cortado", cuja leitura popular harakiri, nos é mais familiar. Durante a Segunda Guerra Mundial, um fenômeno semelhante aconteceu entre os soldados japoneses. Os kamikazes, o vento de Deus, pilotos suicidas, atacaram e surpreenderam os norte-americanos ao final da Segunda Guerra em nome do imperador japonês. Uma morte considerada honrosa, os kamikazes foram reconhecidos como heróis pela sociedade japonesa. Estima-se que 5 mil kamikazes sacrificaram suas vidas durante a guerra. $\mathrm{Na}$ atualidade, os homens-bomba, radicais islâmicos no Oriente Médio que acreditam que o martírio é algo nobre e edificante, desempenham função aparentemente semelhante: motivados 
por questões religiosas sacrificam suas vidas e eliminam muitas outras 4 .

Não se deve deixar de mencionar a atuação de algumas seitas que aparentemente levam seus membros a atitudes extremistas como a de tirarem a própria vida. A história de Jim Jones, um líder fanático que se intitulava "pastor do Templo do Povo”, é paradigmática da relação entre seita religiosa e suicídio coletivo levando, em 1978, aproximadamente novecentas pessoas ao suicídio na Guiana. Em 2000, em Uganda, cerca de oitocentas pessoas que estavam envolvidas com a seita Movimento pela Restauração dos Dez Mandamentos morreram carbonizadas em sua sede, entre tantos outros relatos registrados na história das civilizações modernas 24 .

$\mathrm{O}$ achado que mostra a relação entre suicídio e proporção da população residente com religião de origem pentecostal na realidade é um aprimoramento dos achados da literatura clássica, a partir do trabalho de Durkheim. O autor explorou as diferentes taxas de suicídio entre protestantes e católicos, explicando que o forte controle social entre os católicos resultava em menores índices de suicídio. Uma vez superados alguns problemas metodológicos, a relação se mostra inversa entre tais variáveis por analisar coeficientes ajustados por variáveis que representam setores diferentes e complementares como educação, atividade produtiva, renda, condições de habitação, estado civil e fisiografia.

Em recente estudo com 16.306 adolescentes que relataram pertencer a alguma religião, foram avaliados em sua religiosidade nos aspectos públicos (frequência a atividades religiosas) e privados (qual a importância que dá à religião e qual a frequência com que ora). Embora a religiosidade pública tenha se associado a menor sofrimento emocional, apenas os adolescentes com maior religiosidade privada tinham menor probabilidade de pensamentos ou tentativas suicidas 25 .

Uma área ainda pouco estudada diz respeito aos vários possíveis mecanismos pelos quais a religião pode estar associada a menor risco de suicídio. A hipótese mais tradicional, a maior coesão social, tem sido complementada por fatores mais subjetivos como a crença pessoal e estrutura cognitiva fornecida pelas diversas religiões 22 .

É importante ressaltar que o Brasil não tem produzido de modo consistente pesquisas que colaborem para uma melhor compreensão do tema. Pela diversidade religiosa de nosso país, os pesquisadores nacionais têm a tarefa de ampliar os estudos das relações entre religiosidade e comportamento suicida, bem como a de investigar o quanto os achados de pesquisas realizadas em outras culturas se aplicam à nossa população 22 .
Foi demonstrado que no Chile, sendo representativo do Hemisfério Sul, o índice de suicídio tem a tendência de apresentar uma variação sazonal com maior proporção para os meses cálidos, assim como tem sido demonstrado em numerosas publicações no Hemisfério Norte. Essa observação fica mais clara pela análise mês a mês, demonstrando taxas mais altas em dezembro $(10,6 \%)$ e mais baixas em junho $(7 \%)$. Por meio de análises estatísticas ficou demonstrado que a diferença é significativa 26 .

Estudo desenvolvido no Município de São Paulo detectou diferenças quanto à ocorrência de suicídio no sexo masculino, no período entre 1979 e 2003, totalizando 11.434 casos. Foram observadas diferenças nos suicídios ocorridos na primavera e outono para o sexo masculino. Pela análise de séries temporais, a sazonalidade foi significativa para o período de sete meses também na amostra para o sexo masculino. Algumas das particularidades climáticas da zona tropical poderiam explicar o padrão atípico de sazonalidades de suicídios em uma grande população de área urbana e zona tropical 27.

Alguns trabalhos abordam a influência da diferença de latitude nos casos de suicídio, porém existem restrições metodológicas nestes casos. Não há como isolar o fator climático de fatores socioeconômicos e culturais, pois estes últimos espacialmente variam muito. No caso do suicídio sabe-se que os fatores socioeconômicos e culturais possuem forte influência em seu desfecho. Basta verificar a distribuição espacial heterogênea das taxas de suicídio no mundo. Se a elevada radiação fosse o fator de risco dominante, a zona intertropical deveria concentrar altas taxas de suicídio, e não é o caso. Logo, a maioria dos estudos que aborda a influência de fatores climáticos no suicídio é análise temporal, sendo comuns trabalhos sobre a sazonalidade do suicídio 28 .

Esse tipo de estudo foi realizado por Nejar et al. 29 na cidade de São Paulo. Constatou-se que não existe o comportamento sazonal no suicídio, bem como a sua correlação com a radiação solar global na cidade de São Paulo, no período entre 1996 e 2004. Nessa análise temporal foram utilizados dados diários de radiação proveniente de duas estações meteorológicas, bem como as ocorrências diárias de suicídio. O estudo também sugere que o fenômeno da sazonalidade do suicídio ocorra principalmente na zona temperada, onde as quatro estações do ano são bem definidas e a amplitude da radiação solar global anual é mais significativa em relação à zona intertropical 29.

Estudos epidemiológicos referem que, em geral, as taxas de suicídio são maiores entre os solteiros, viúvos e divorciados do que entre os 
casados, e são maiores entre as pessoas que não têm filhos, bem como naquelas com história clínica de depressão e usuários de álcool 6 .

Um trabalho desenvolvido sobre suicídio no Município de Teresina (Piauí), no período de 2000-2005, por meio de laudos do Instituto de Medicina Legal evidenciou uma proporção maior de suicídio entre os homens (71,3\%), com maior incidência entre os jovens e predomínio de solteiros $(54,9 \%)$. O grupo ocupacional com o maior percentual de ocorrência foi o de estudantes $(23,8 \%)$. O método mais frequente foi o de enforcamento (66\%), seguido de arma de fogo $(13,1 \%)$. A realização de intervenções em busca da diminuição das taxas existentes é primordial, nesse caso, pois essas corresponderam ao quarto lugar em relação a todas as mortes de causas violentas ocorridas no município 30 .

O nível educacional é uma das variáveis mais citadas nos estudos epidemiológicos a respeito do suicídio, porquanto merece destaque uma vez que sua ocorrência está relacionada a baixos níveis educacionais 31,32 . O que tem de ser levado em consideração nesse caso é de fato saber se o baixo nível educacional já não estaria relacionado a algum tipo de transtorno mental ou a tipos específicos de comportamento, como uso de droga que antecedesse e reduzisse a possibilidade de o indivíduo ter um grau de instrução mais elevado.

Segundo a teoria sociológica durkheimiana, em períodos de crises econômicas faz-se necessário a diminuição do padrão de vida, ajustando-se a esta condição. No caso dos ricos isso se torna muito difícil, pois acostumados ao ímpeto de querer sempre mais, seguindo as suas paixões e desejos, é difícil frear esse movimento. Já para os pobres, essa condição funciona como fator de proteção ao suicídio porque é ela mesma um freio. Há maior conformação com o que se pode ter, agindo com moderação e tendo maior consciência dos seus limites 9 .

Não existe consenso na literatura sobre a relação entre suicídio e nível socioeconômico 14 . De acordo com Rehkopf \& Buka 14, os motivos para essas diferenças de resultados estão ligados a questões metodológicas. Entre as possibilidades estão o tamanho da população agregada, a medida das características socioeconômicas das áreas usadas, diferenças reais na associação por região e população onde os estudos foram feitos, inclusão de diferentes variáveis de confusão, delineamento do estudo, entre outras. Segundo a OMS 12, os fatores de risco são os extremos sociais, ou seja, baixa e alta rendas.

Diante desses resultados pode-se inferir que o suicídio possui duas vertentes de análise constituídas por fatores relacionados aos contextos social e interpessoal nos quais os indivíduos estão inseridos, ou seja, determinantes de ordem intrínseca, apropriados geralmente em estudos efetuados por profissionais de saúde; e os determinantes de ordem extrínseca, sendo estes o foco principal deste trabalho. Muito embora tal divisão seja meramente facilitadora da compreensão desses fatores, ressalta-se que sua atuação ocorre de forma conjunta e articulada. Pode-se afirmar, portanto, que o suicídio demanda ações intersetoriais de enfrentamento para a redução dos danos, porquanto seu estudo assume caráter multidisciplinar e transdisciplinar. 


\section{Resumo}

A epidemiologia tem focado a violência como um dos problemas da Saúde Pública. Dentre as categorias da violência encontra-se o suicídio. Este estudo descreve associações entre suicídio e aspectos sociodemográficos. Usa metodologia ecológico-transversal por meio de técnicas de correlação e regressão linear múltipla (backward). A mortalidade proporcional em relação ao total de óbitos foi o melhor desfecho para modelagem $\left(R^{2}=0,41\right)$. As variáveis resultantes: porcentual da população residente com religião de origem pentecostal, porcentual de pessoas com 10 anos ou mais de idade com estado civil solteiro, média de anos de estudos, altitude para municípios da divisão político-administrativa vigente $2.000 \mathrm{~m}$, percentual de moradores em domicílios particulares permanentes com ausência de banheiro, percentual de pessoas com 10 anos ou mais de idade ocupadas no setor "educação" e porcentual de pessoas com 10 anos ou mais de idade com rendimento nominal de até um salário mínimo, todas estatisticamente significantes no nivel de 0,05. O resultado encontrado vem reforçar a ideia da influência de fatores causais extrínsecos na determinação desse desfecho.

Suicídio; Mortalidade; Fatores de Risco; Modelos Lineares

\section{Colaboradores}

J. G. Bezerra Filho, G. L. Werneck, R. L. F. Almeida, M. I.V. Oliveira e F. B. Magalhães participaram da análise e interpretação dos dados, redação do artigo, revisão crítica do conteúdo intelectual e da aprovação da versão final.

\section{Referências}

1. Viana GN, Zenkner FM, Sakae TM, Escobar BT Prevalence of suicide in the South of Brazil, 20012005. J Bras Psiquiatr 2008; 57:38-43.

2. Organização Mundial da Saúde. Relatório mundial sobre violência e saúde. Genebra: Organização Mundial da Saúde; 2002.

3. Botega NJ. Suicide: moving away umbrage towards a National Prevention Plan. Rev Bras Psiquiatr 2007; 29:7-8.

4. Gregório SB. Suicídio. http://www.ceismael.com. $\mathrm{br} /$ artigo/suicidio-e-espiritismo.htm (acessado em 10/Dez/2009).
5. Mello-Santos CD, Bertolote JM, Wang YP. Epidemiology of suicide in Brazil (1980 - 2000): characterization of age and gender rates of suicide. Rev Bras Psiquiatr 2005; 27:131-4.

6. Secretaria de Saúde de Fortaleza. Epidemiologia do suicídio. Boletim de Saúde de Fortaleza 2009; 13:5.

7. Meneghel SN, Victora CG, Faria NMX, Carvalho LA, Falk JW. Características epidemiológicas do suicídio no Rio Grande do Sul. Rev Saúde Pública 2004; 38:804-10. 
8. Marcondes Filho W, Mezzaroba L, Turini CA, Koike A, Motomatsu Junior A, Shibayama EEM, et al. Tentativas de suicídio por substâncias químicas na adolescência e juventude. Adolesc Latinoam 2002; 3:1-5.

9. Durkheim E. O suicídio. São Paulo: Martin Claret; 2008.

10. Teixeira RR. Três fórmulas para compreender "O suicídio" de Durkheim. Interface Comun Saúde Educ 2002; 6:143-52.

11. Organização Pan-Americana da Saúde. Prevenção do suicídio - manual dirigido a profissionais das equipes de saúde mental. Washington DC: Organização Pan-Americana da Saúde; 2006.

12. Organização Mundial da Saúde. Prevenção do suicídio: um manual para médicos clínicos gerais. Genebra: Organização Mundial da Saúde; 2000.

13. Durkheim E. O suicídio: um estudo sociológico. Rio de Janeiro: Zahar Editores; 1982.

14. Rehkopf DH, Buka SL. The association between suicide and the socio-economic characteristics of geographical areas: a systematic review. Psychol Med 2006; 36:145-57.

15. Romeder JM, McWhinnie JR. Potential years of life lost between ages 1 and 70: an indicator of premature mortality for health planning. Int J Epidemiol 1977; 6:143-51.

16. Vermelho LL, Costa AJL, Kale PL. Indicadores de saúde. In: Medronho RA, organizador. Epidemiologia. São Paulo: Atheneu; 2002. p. 33-55.

17. Hosmer DW, Lemeshow S. Model-building strategies and methods for logistic regression. In: Hosmer DW, Lemeshow S, editors. Applied logistic regression. New York: John Wiley \& Sons; 1989. p. 82-134.

18. Silva AB. Sistemas de informações geo-referenciadas: conceitos e fundamentos. Campinas: Editora da Unicamp; 2003.

19. Assunção RM. Estatística espacial com aplicações em epidemiologia, economia e sociologia. São Carlos: Associação Brasileira de Estatística; 2001.

20. Morgenstern, H. Ecologic studies. Modern epidemiology. Boston: Lippincott Williams \& Wilkins Publishers; 1998.
21. Barreto ML, Carmo EH. Mudanças em padrões de morbimortalidade: conceitos e métodos. In: Monteiro CA, organizador. Velhos e novos males da saúde no Brasil. A evolução do país e de suas doenças. São Paulo: Editora Hucitec/Núcleo de Pesquisas Epidemiológicas em Nutrição e Saúde, Universidade de São Paulo; 2000. p. 17-30.

22. Almeida AM, Lotufo Neto F. Religião e comportamento suicida. Rev Bras Psiquiatr 2006; 28:53-60.

23. Oliveira RS. Alguns argumentos contra o suicídio (I). http://www.espirito.org.br/portal/artigos/ge ae/argumentos-suicidio-1.html (acessado em 11/ Ago/2006).

24. Michalick MT. Suicídio - uma abordagem espiritual. Revista Cristã de Espiritismo 2009; (43):21-7.

25. Nonnemaker JM, McNeely CA, Blum RW. Public and private domains of religiosity and adolescent health risk behaviors: evidence from the National Longitudinal Study of Adolescent Health. Soc Sci Med 2003; 57:2049-54.

26. Retamal P, Humphreys D. Occurrence of suicide and seasonal variation. Rev Saúde Pública 1998; 32:408-12.

27. Bando DH, Scrivani H, Morettin PA, Teng CT. Seasonality of suicide in the city of Sao Paulo, Brazil, 1979-2003. Rev Bras Psiquiatr 2009; 31:101-5.

28. Bando DH. Padrões espaciais do suicídio na Cidade de São Paulo e seus correlatos socioeconômicoculturais [Dissertação de Mestrado]. São Paulo: Programa de Pós-graduação em Geografia Física, Faculdade de Filosofia, Letras e Ciências Humanas, Universidade de São Paulo; 2009.

29. Nejar KA, Bensenhor IM, Lotufo PA. Sunshine and suicide at the tropic of Capricorn, São Paulo, Brazil, 1996-2004. Rev Saúde Pública 2007; 41:1062-4.

30. Parente AC, Soares RB, Araujo AR, Cavalcante IS, Monteiro CF. Characterization of suicide cases in a Brazilian northeastern capital. Rev Bras Enferm 2007; 60:377-81.

31. Menezes PR. Prognóstico da esquizofrenia. Rev Bras Psiquiatr 2000; 22:18-20.

32. Borges VR, Werlang BG. Estudo de ideação suicida em adolescentes de 15 a 19 anos. Estud Psicol (Natal) 2006; 11:345-51.

Recebido em 11/Mar/2010

Versão final reapresentada em 03/Jun/2012

Aprovado em 02/Fev/2012 